\title{
Use of resistivity measurements to detect urban caves in Mexico City and to assess the related hazard
}

\author{
R. G. Antonio-Carpio ${ }^{1,2}$, M. A. Pérez-Flores ${ }^{1}$, D. Camargo-Guzmán ${ }^{2}$, and A. Alanís-Alcantar ${ }^{3}$ \\ ${ }^{1}$ Depto. de Geofisica Aplicada, CICESE, Ensenada, México \\ ${ }^{2}$ Profesionistas en Geocontrol Co., México \\ ${ }^{3}$ Depto. de Reabilitación de Minas, Delegación Alvaro Obregón, México City, México
}

Received: 12 November 2003 - Revised: 6 September 2004 - Accepted: 12 September 2004 - Published: 30 September 2004

\begin{abstract}
In the XIX century when Mexico City was much smaller than at present, there was non-regulated mining of building materials in a region of tuffs northwest of the city in an inhabited countryside. With the growth of the city during the XX century, this region was increasingly populated and in the 1970's many two-level bricks houses were built, without regard for underground caves created by the earlier extractions. Some ground sinkings in adjacent areas alarmed the residents who now are worried about this permanent hazard. An association of residents contracted a private company for a geophysical study in order to know the distribution of the caves.
\end{abstract}

Resistivity measurements were taken in the area to detect the caves in order to alert city authorities. Resistivity data along most of the streets were collected with the array pole-dipole that consisted of three grounded electrodes. We performed 2-D dimensional inversions to the data in order to get a 2-D resistivity image of every street. This is similar to a resistivity cross-section of the ground but obtained from the inversion of pole-dipole and Schlumberger resistivity data simultaneously. Using the information of previous drills we modified our programming code in order to perform constrained inversion and to get more accurate resistivity models in agreement with the drills. From the resistivity models obtained for every street it was possible to produce a map which shows the horizontal distribution of the resistive bodies at a depth of $12 \mathrm{~m}$. These resistive bodies show coherent alignments that seem to correspond with a distributions of interconnected caves or tunnels used for extracting the sandy-tuffs. From these kind of interpretation method it was intended to get a more accurate horizontal distribution of the excavated areas in order to better know the urbanized area affected and lead the authorities to remedy the area with refill material.

Correspondence to: M. A. Pérez-Flores

(mperez@cicese.mx)

\section{Introduction}

The area of study is located northwest of Mexico City (colonia Prados La Providencia, Delegación Alvaro Obregón), close to Sierra de Las Cruces, which is constituted of small volcanoes of andesites, breccias and tuffs of basaltic composition. The area of study is a small plateau with a sequence of clays and sands with tuffs, surrounded by $20 \mathrm{~m}$ deep ravines. The plateau is flat and slightly dipping toward SE.

Around 1870 this area was in the countryside and it was not included in the metropolitan area of Mexico City. The area was widely used by small companies to extract material for making bricks. Historical records report that most of these materials were sold in capitol. Many of Mexico City's buildings at that time used these bricks. At that time, there was no regulation over the extraction techniques and no record of the precise locations of the caves was taken. The extraction was carried out using picks, shovels and donkeys in the caves, according to the technique of "Rooms and Pillars". This technique consists of digging a room and leaving an intact pillar of material at the center to support the roof. The rooms can be of irregular shape and interconnected with others.

The ravines were used as access to reach the sandy tuffs located close to their bottom. In this area the entrances to the mines were on the cliffs but at other sites digging was started from the surface.

Almost $60 \mathrm{~km}^{2}$ of this region was affected by man-made caves in order to extract construction materials for the growth of Mexico City. Throughout the XX century the city grew but only in 1970 it did reach this region. In the 1960's the extraction over the region was stopped and the caves were finally abandoned. With a paucity of regulation and the cheap prices for the land, many people began to build brick houses of one and two levels. The only regulation forbade further extraction, but that had already stopped. The plateau is now full of masonry houses and streets with 15 years old pavement (Fig. 1). 


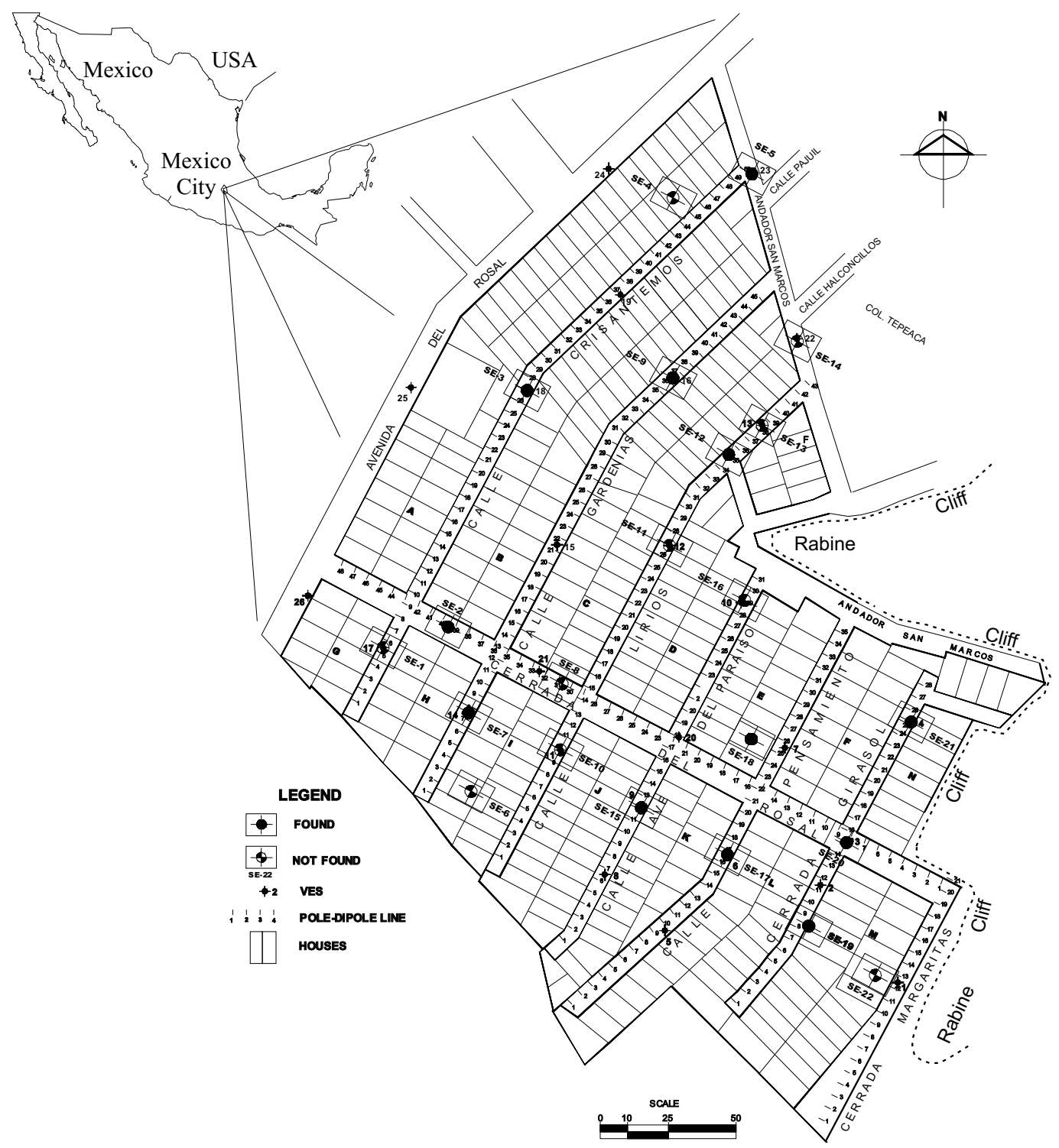

Fig. 1. The prospecting area is located Northwest of Mexico City. Data consisted of pole-dipole arrays along 8 streets of the urban sector and 26 vertical electrical soundings (VES; Schlumbergers). From the first interpretation 22 sites were proposed for drillings and 12 cut caves (filled circles).

The uncharted labyrinth of caves represents a real danger to the area's residents. It is presumed that the tunnels run between 10 and $15 \mathrm{~m}$ of depth because this is the depth where the exploitable sandy tuff layer is located. The caves preservation status is unknown; they could be fractured or even partially collapsed. The entrances were located on the cliffs, but were intentionally buried by the residents in order to stop thieves when the area began to be urbanized. The bottom of the ravines is now covered by garbage, material debris and vegetation. The caves must be interconnected to form tunnels. Knowledge of the distribution of the tunnels is crucial for evaluating the areas of greater hazard and to put remedy through civil engineering. To do so, however an accurate determination of the spatial distribution of the tunnels is needed.
In 2001 a residents association contracted a private company to apply geophysics in order to determine the location of the caves. The company applied the direct current (DC) resistivity method. They used pole-dipole profiles along the streets and vertical electrical soundings (VES or Schlumberger) at specific sites of the streets (Fig. 1). The streets have concrete pavement, so the field crew needed to drill small holes to introduce the electrodes to have good galvanic contact with the soil below the pavement. They used four electrodes, two as sources and two as receivers. One source electrode was grounded far enough to neglect its effect in the receivers. The constant distance between receiver electrodes was of $5 \mathrm{~m}$. The distance between the source electrode and the nearest receiver electrode varied with 5, 10, 15, $20, \ldots$ and $55 \mathrm{~m}$. The Schlumberger soundings had a maximum source distance $(\mathrm{AB})$ of $120 \mathrm{~m}$. 
The equipment consisted of a transmitter GEOELEC model Tlali T-1500 with a maximum of 10 amperes of current. As a receiver, a digital multimeter with a natural potential suppressor was used. The maximum current used in field did not exceed 2 amperes.

The prior interpretation of the Schlumberger soundings (Antonio-Carpio, 2003) considered a stratified subsurface (layers). The pole-dipole pseudo-sections were interpreted qualitatively (Antonio-Carpio, 2003). From this interpretation twenty-two sites were suggested for drilling, and 12 of them were successful in their prediction cutting cavities $(1 \mathrm{~m}$ in average, except SE-7 with $2 \mathrm{~m}$ ). These drills reached a maximum of 21 to $25 \mathrm{~m}$ of depth.

Data seem consistent, of good quality and with low level of noise, but the interpretation has implicit errors because of the qualitative interpretation of the pseudo-sections. Pole-dipole is an asymmetric array and the geometry of the pseudosection depends on the direction of the array, showing an inclination in the anomalies that does not exist. Those asymmetries can cause additional misunderstandings when interpreting directly from the pseudo-section.

In this work, we reinterpreted those data, using the more advanced techniques for 2D interpretation of DC resistivity data in order to get more realistic. As a result, we were able to map the tunnel distribution.

\section{Geological background}

The Colonia prados la Providencia is located in the eastern part of the Mexico city, within the Mexican Basin tectonic province. This basin is located in the central part of the Trans-Mexican Volcanic belt and it has an approximate area of $9000 \mathrm{~km}^{2}$. The basin altitude of $2200 \mathrm{~m}$ above sea level constitutes the highest valley in the region, and it is surrounded by mountains that reach elevations over $5000 \mathrm{~m}$ above sea level.

The Basin of Mexico is a high altitude volcanic structure that is bounded by the Sierrra Nevada and Rio Frio at the east, the Sierra de las Cruces at the west, the Sierras Tezontlalpan and Pachuca to the north and the Sierra Chichinautzin to the south. The basin contains a thick volcano-sedimentary sequence, including lake sediments. Within the basin, there are several volcanic structures, such as Sierra Santa Catarina and the volcanoes La Estrella, Peñon Viejo, Chimalhuacán, Xico. Some of these volcanic structures have been quarried for construction materials in the past and additionally the area provides part of the ground water supply for Mexico City (Urrutia-Fucugauchi, 1995). The closest structure to Colonia Prados la Providencia is Sierra de las Cruces, who had Upper Quaternary through Lower Tertiary volcanic activity, driving out pumice ash to the NE (Fries, 1960).

This mixture of soft volcanic material constitutes the Tarango formation that covers the area of interest (Mooser, 1975). In Table 1 the stratigraphic column for the area is shown. Layer 3, which is located between 12 to $14 \mathrm{~m}$ depth in the area of study, was the most used during the years of
Table 1. Description of the Tarango formation.

1 Toltosingo soil. Dark color with high content of organic material.

2 Tacubaya and Becerra soils: sandy-clays inter-digitized with caliche and pumice tuff. Mainly dark yellow.

3 Lahar with sharp clasts of 2.5 to $10 \mathrm{~cm}$ in a sandy matrix of blue to gray color.

4 Clay-tuff of yellow to brown color with caliche bands.

5 Coarse sandy-tuff of dirt white color, unconsolidated.

6 Clay-tuff of yellow to brown color with caliche bands.

exploitation. Layer 5 was also exploitable in other areas, but this did not occur at Prados La Providencia since it is located below the bottom of the ravines.

\section{Method}

Resistivity inversion can be solved by the Laplace differential equation, using finite differences (Sasaki, 1989) or finite elements. Another way is by mean of Integral Equations. In this branch, several authors have used the scattering equation (Hohmann, 1975) and then approximation for lowresistivity contrast (Loke and Barker, 1996; Li and Oldenburg, 1992). We use a non-linear integral equation (GómezTreviño, 1987) with the same assumption for low-resistivity contrasts (Cavazos-Garza and Gomez-Treviño, 1989; PérezFlores et al., 2001). In Pérez-Flores et al. (2001) the equation has more physical meaning because the unknown resistivity (logarithm of $\rho$ ) of the ground is directly related with the apparent resistivity $\left(\rho_{a}\right)$ conventionally measured merely through a weighting function $(K)$,

$\log \rho_{a}\left(x_{A}, X_{B}, X_{M}, X_{N}\right)=$

$\iint K\left(X_{A}, X_{B}, X_{M}, X_{N}, X, Z\right) \log \rho(x, z) d x d z$,

where $\left(x_{A}, x_{B}\right)$ are the position of the source electrodes, $\left(x_{M}, x_{N}\right)$ for the receivers and $\rho(x, z)$ is the unknown resistivity of the ground that can vary in the horizontal direction $x$ and with depth $z$. Equation (1) was defined for a conventional four electrodes array as dipole-dipole, Schlumberger and Wenner. Resistivity in Eq. (2) does not change in $y$ direction, thus this equation assumes that the bodies are elongated in that direction; they are bidimensional bodies (2D). More details of Eq. (1) are found in Pérez-Flores et al. (2001).

For many apparent resistivities taken on surface, a linear system of equations can be defined,

$\mathbf{O}=\mathbf{G P}$,

where $\mathbf{O}$ is the logarithm of all the apparent resistivities taken along a line or along a street in our case, $\mathbf{G}$ the weighting function for all the observations and unknowns and $\mathbf{P}$ the logarithm of the unknown resistivities under the ground. 


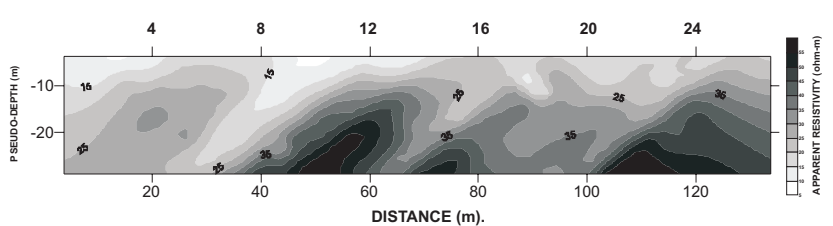

Fig. 2. Pole-dipole pseudo-section for the Girasol Street. Resistive anomalies are assumed to be associated with caves or tunnels. This array is asymmetrical and shows an inclination in the apparent resistivity anomalies.
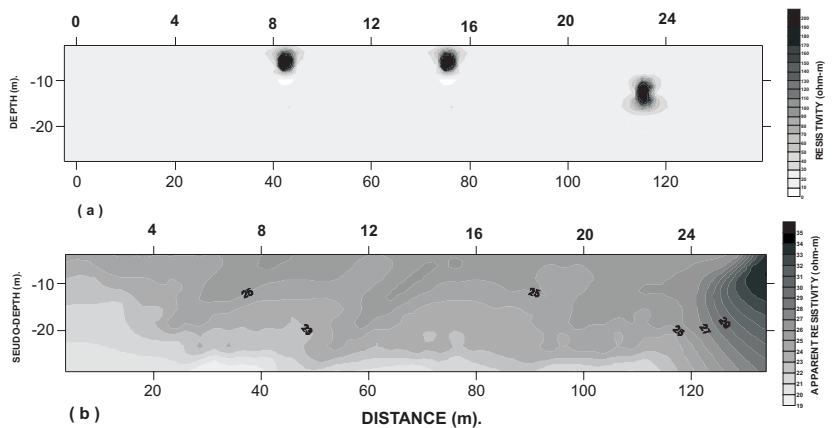

Fig. 3. (a) Model proposed after three drillings cutting caves in Girasol Street. It consists of three resistives within a homogeneous half-space obtained from the average of the data. (b) Response computed for the model in the form of pseudo-section as in Fig. 2. The small resistives are not enough to justify the anomalies shown in Fig. 2.

Equation (2) is solved by means of quadratic programming (QP; Gill et al., 1986). This kind of optimization method (QP) allows equality and inequality constraints over the unknowns as follows,

$\rho_{l} \leq \rho \leq \rho_{u}$,

where $\rho_{l}$ are the lower and $\rho_{u}$ the upper value that certain unknown resistivity can take.

The program for Inversion of bidimensional bodies with Eq. (2) for dipole-dipole data is available at no cost on http: //arcada.cicese.mx/geofisica/dc/direct-current.html.

Pole-dipole array was used for detecting the caves under the ground. Theoretically, one electrode is taken to infinity. Practically, one electrode is grounded very far from the measurements area, in order to close the source circuit and not affect the measurements. Numerically, it is equivalent to taking off one point source. We modified Eq. (1) to work with one source electrode $\left(x_{A}\right)$ and two receivers $\left(x_{M}, x_{N}\right)$, leading to the equation,

$\log \rho_{a}\left(x_{A}, X_{M}, X_{N}\right)=$

$\iint K_{3}\left(X_{A}, X_{M}, X_{N}, X, Z\right) \log \rho(x, z) d x d z$.

The weighting function from Eq. (4) is different from Eq. (3) and its calculation saves approximately $40 \%$ of time.

With Eq. (4) and the constraints of Eq. (3) it was possible to introduce the information reported by the 22 drillings.
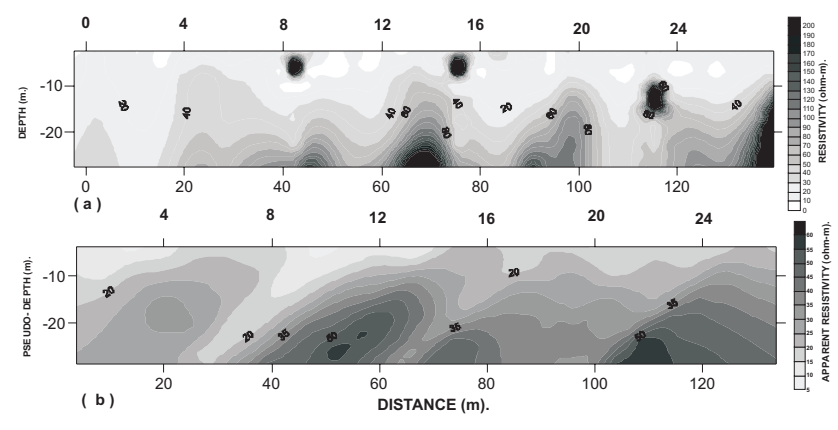

Fig. 4. (a) Best model obtained for Girasol Street. It shows the three caves and with dashed line the top of other wider resistives. (b) Response for the model in the form of apparent resistivity pseudosection (Fig. 2).


Fig. 5. Comparison for the three Schlumbergers measured in Girasol Street and the responses of two different models. Diamonds are the data. Circles show the response for the model in Fig. 3. Solid line represents the response for the model in Fig. 4.

\section{Models obtained for the profiles}

Figure 2 shows the apparent resistivity pseudo-section for Girasol Street. This was the image first used for the prediction of the caves location. There are several resistives with a consistent inclination. This inclination is due to the asymmetry of the pole-dipole array. This additional feature difficult more the direct interpretation from the apparent resistivity pseudo-section. Bidimensional inversion takes this 


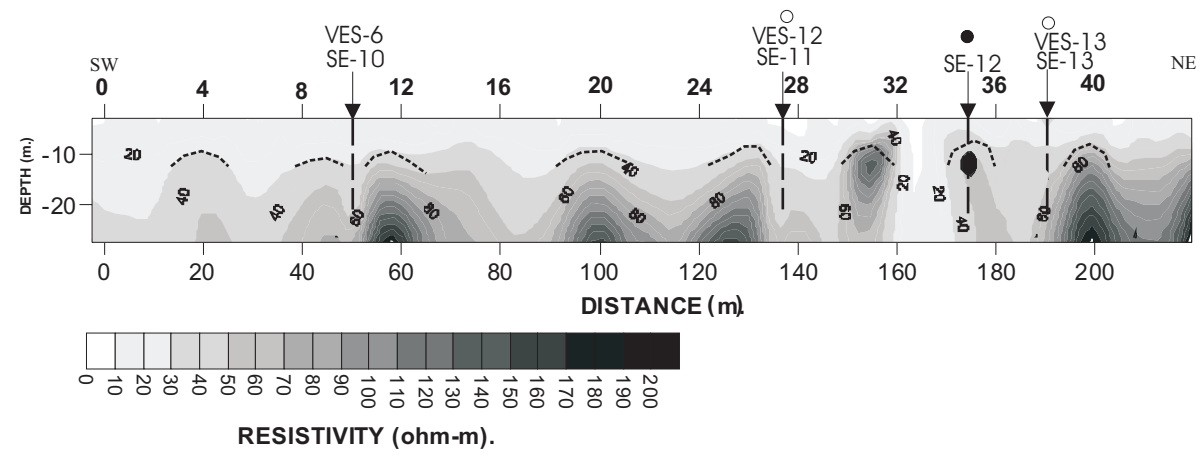

Fig. 6. Resistivity image obtained from the inversion at Lirios street.

asymmetry into account. Three successful drillings in Girasol Street were done, encountering caves at depth between 8 and $14 \mathrm{~m}$ depth, which is the presumed level of extraction. The drill reached at depth of 20 to 22 , but no more caves were found.

As a first test, we did forward modeling assuming a constant half-space perturbed by the three caves reported by the drillings. The average resistivity obtained from the pseudosection was used for assuming the constant resistivity host rock (Tarango formation) as shown in Fig. 3a. The computed response (Fig. 3b) is different from the data (Fig. 2). In Fig. 5 we compare the Schlumberger responses (circles) and the data (diamonds), interpreting bidimensionally by Eqs. (1) and (2). Neither the Schlumberger soundings resembles to the data, thus more resistives must exist in order to justify the whole pseudo-section.

Therefore, the inversion of the pole-dipole data was performed by means of Eq. (4). The linear system of equations was solved (Eq. 2) with quadratic programming, minimizing the difference between the data and the response of the best model obtained plus one parameter that controls the roughness of the model (Constable et al., 1987).

Joint inversion of the Schlumberger soundings by Eq. (1) and pole-dipole inversion with Eq. (4) were performed at the same time. This procedure solves the linear system of equations (Eq. 2), minimizing their respective differences between the data and the best model response. The information obtained from the 22 drillings was incorporated in Eq. (2) by mean of equality constraints. For example, in Girasol Street one of three drills cut an empty space between 5 and $6 \mathrm{~m}$ and then the drill continued until $22 \mathrm{~m}$. The affected cells were identified for the inversion process: from 0 to $5 \mathrm{~m}$ anything but not a resistive is allowed, from 5 to 6 a $1000 \mathrm{ohm}-\mathrm{m}$ a resistive and from 6 to $22 \mathrm{~m}$ a non-resistive. In cases where the drill did not find a cavity, the inversion was informed, allowing a non-resistive. This was possible by manipulating equality and inequality constraints.

Proceeding with this method, we obtained the best model shown in Fig. 4a. In Fig. 4b the apparent resistivity response for that model is shown. Comparing Figs. $4 \mathrm{~b}$ and 2 a very good match is demonstrated. In Fig. 5 the Schlumberger responses for the three soundings (line) are shown. Again, there is a good fit with the data (diamonds).
It was demonstrated that subsurface is more complex than the simplest assumption of three holes in a constant subsurface (Fig. 3) and that other resistive bodies must exist in order to account for the whole data. In other words, other caves must exist.

The dash line (Fig. 4a) indicates all the resistives that rise between 10 and $14 \mathrm{~m}$ (depth reported for the third layer in Tarango formation). In the resistivity image (Fig. 4a) the resistives look wider and deeper. We know that caves were not designed to be very wide, but the resistive anomaly can reflect a complete loop of tunnels as miners used the Room and Pillar technique. The deeper part of the anomaly seems resistive, meaning that the data (Fig. 2) did not show the end of the resistive caves. Maybe, current injected was not suffient or it did find high resistance obstacles to reach deeper parts.

\section{Resistivity image for a street profile and tunnel distri- bution}

The model obtained for Lirios Street (Fig. 6) consists of data from a pole-dipole section and the vertical electrical soundings (VES-6, VES-12 and VES-13), as well as four drillings (SE-10, SE-11, SE-12 and SE-13). The inversion took all the data and constrains with the drillings available. Only drilling SE-12 cut a cave. This cave is not enough to produce the whole anomaly measured. There are other resistive bodies under stations 12, 20, 26, 31 and 40. The drillings SE-10, SE-11 and SE-13 did not cut a cave, but SE-12 did it. The program code was informed as inequality and equality constraints, respectively.

The other profiles were processed in the same way as it was done in Lirios and Girasol Streets. It is not the intention to describe each other. All the profiles show that several resistives are present in those resistivity cross-sections. Immediately, we can suspect that those resistives associated with the caves can exhibit a spatial regular pattern.

\section{Tunnels distribution}

The eight-resistivity sections with the corresponding Cartesian coordinate for every station were taken and an interpolated map of resistivities (slice) at $12 \mathrm{~m}$ was drawn (Fig. 7). 


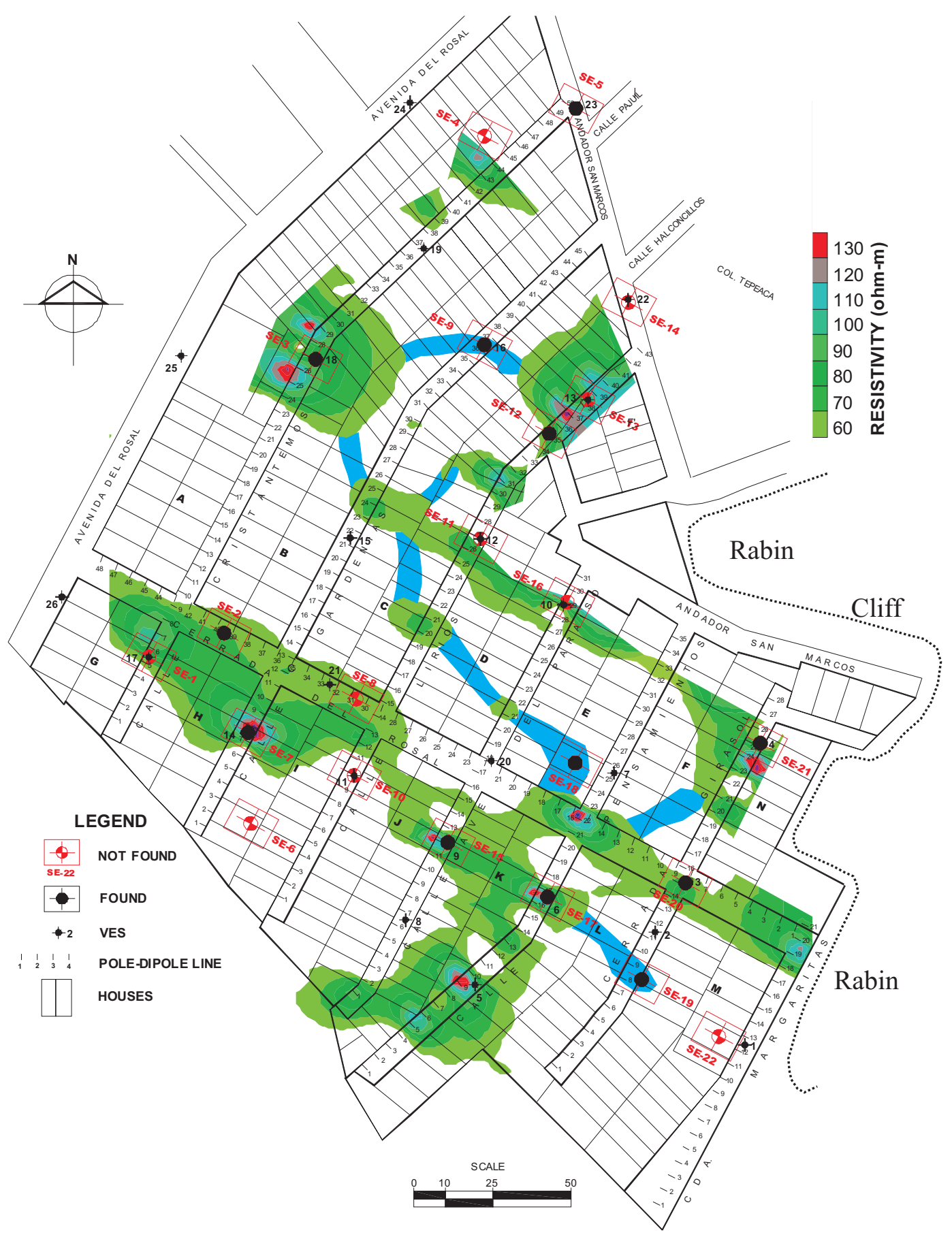

Fig. 7. Resistivity slices at $12 \mathrm{~m}$ depth over the streets map. Only resistive contours are shown. Plot suggests that resistive distribution may correspond with tunneling. Wider anomalies may correspond to Room and Pillars loops. Blue thick lines are suggested connections between resistives, representing the areas of greater hazard.

This map or horizontal slice was used to visualize the linear correlation between the profiles of the streets.

Figure 7 shows the resistivity slice at $12 \mathrm{~m}$ depth, where the caves or tunnels are located. From the linear trends we can infer that the caves form tunnels or interconnected rooms and pillars. Only the high resistivity contours were plotted over the street map. Regions with no data, which appeared at the border of the area, were erased from the interpolated map. Despite the distance of 30 to $35 \mathrm{~m}$ between two streets, there is a consistent linear correlation between their respective resistivity cross-sections. A thick blue line was drawn where we believe that there is a correlation between resistives, although the krigging interpolator found the size of the resistives to be small. At the SE of the area there is a linear trend that ends at the ravine. This likely corresponds to a tunnel entrance on the cliff close to Margarita Street. This linear 
trend runs $240 \mathrm{~m}$ toward the NW and is consistent in all profiles. The trend was plotted to Crisantemos Street (at the NW), but it may continue further. This seems to be the main tunnel or a set of rooms and pillars in the area. At the south of this trend there is another resistive centered in Pensamientos Street (station 6 to 10). We suggest that these are several tunnels or Rooms connected to the principal. From Pensamientos Street almost to the North there is another path connecting the main tunnel with a large resistive under station 29 in Crisantemos Street. This path is supported for three resistives that cross in Paraiso, Lirios and Gardenias streets and a cave was detected near station 25 at Pensamientos street. The wide resistive in station 28 at Crisantemos Street suggests a complex of Room and Pillars. Close to station 26 in Girasol Street another resistive trend begins. This may continue to the cliff and be another entrance. Despite main entrances were erased 40 years ago, some holes are shown over the cliff, but they are small in size $\left(0.5 \mathrm{~m}^{2}\right)$ and collapsed.

\section{Conclusions}

In Fig. 7 we estimate a total length of $1100 \mathrm{~m}$ of tunnels. Considering linear paths we initially estimate a volume of $4400 \mathrm{~m}^{3}$ of extracted material based on the following assumptions. The width and height of the original tunnel is not known, but considering a person and a donkey in movement, we estimate dimensions of $2 \times 2 \mathrm{~m}$. Further, the room and pillars technique support a maximum width of $6 \mathrm{~m}$. Considering linear paths we initially estimated a volume of $4400 \mathrm{~m}^{3}$ of extracted material but considering at least two sides for the rooms, the volume may increase to $8800 \mathrm{~m}^{3}$. Also, there is the possibility that narrower tunnels not detected were presents. The volume may be a little bigger. This quantity is important for a priory estimation of refill material needed to remedy this hazardous area.

After more than 100 years from the beginning of the extractions and 50 years since its abandonment, the condition of the tunnels continues to be unknown.

The roofs are the most susceptible for cracking producing an upward propagation and posterior collapsing.

If we consider that the top of the tunnel is located approximately at $12 \mathrm{~m}$ depth with an average density of $2.2 \mathrm{gr} / \mathrm{cm}^{3}$, there is a compression of approximately $30 \mathrm{ton} / \mathrm{m}^{2}$ on the roofs of tunnels. The later construction of two level-houses added 2 to 3 ton $/ \mathrm{m}^{2}$, representing a $10 \%$ excess. Humidity, seismic activity, traffic and lithostatic weight plus the excess of mass of the houses can precipitate cracking around the tunnels. Presently, there are no surface evidences of fracturing (sidewalks, roads or houses), but collapses before the urbanization may have occurred, and those affectations to the surface refilled by the people, showing presently an undisturbed surface. It is unnecessary to wait for surface evidences of cracking in order to alert authorities to the hazard posed in this urbanized zone of Mexico City. Unfortunately, there are no records of the exploitation, only people's narratives collected by authorities. Today, there are some col- lapsed holes on the cliff walls. Main entrances to the tunnels have been erased and there is vegetation and garbage over the ravines. Through joint inversion of Schlumberger and poledipole data constrained by the drillings it was possible to get a sharper image of the subsurface and to identify and map the horizontal distribution of the tunnels through the resistivity slice at $12 \mathrm{~m}$ (Fig. 8). Future work to identify narrower tunnels can occur during the remediation drilling using wider drilling and descents with topographical equipment as it has done in other sites.

Acknowledgements. We want to thank CONACYT for their financial support; F. Suárez for their valuable comments over the geology; profesionistas en Geocontrol Company for the permission for using the data; for the useful comments of the reviewers; $\mathrm{H}$. Benítez for his help with the drawings; F. Camarillo (Delegación Alvaro Obregón) for facilitating the historical records of the area and to K. Englander for reviewing the manuscript.

Edited by: F. Guzzetti

Reviewed by: V. Lapenna and another referee

\section{References}

Antonio Carpio, R. G.: Application of the DC geoelectrical method for detecting caves in colonia Prados La Providencia, Mexico City, Bachelor Thesis, Mexican Polytechnic Institute, 2003.

Cavazos Garza, R. and Gómez-Treviño, E.: Hacia la inversión tridimensional de anomalías de resistividad y polarización inducida, Geofísica Internacional, 28, 481-505, 1989.

Constable, S. Parker, R., and Constable, C.: Occam's inversion: A practical algorithm for generating smooth models from electromagnetic data, Geophysics, 52, 289-300, 1987.

Fries, C.: Geología del estado de Morelos y de partes adyacentes de México y Guerrero, región central meridional de México, Bol. del Instituto de Geología, UNAM, 60, 236-242, 1960.

Gill, P., Hammarling, S., Murray, W., Saunders, M., and Wright, M.: User's guide for LSSOL, A package for constrained linear least-squares and quadratic programming, Stanford Univ. Technical Report SOL-886-1, 1986.

Gómez-Treviño, E.: Nonlinear integral equation for electromagnetic inverse problems, Geophysics, 52, 1297-1302, 1987.

Hohmann, G. W.: Three-dimensional induced polarization and electromagnetic modeling, Geophysics, 40, 309-324, 1975.

Li, Y. and Oldenburg, W. D.: 3-D inversion of induced polarization data, Geophysics, 65, 1931-1945, 1992

Loke, M. H. and Barker, R. D.: Rapid least-squares inversion of apparent resistivity pseudosections using a quasi-Newton method, Geophysical Prospecting, 44, 131-152, 1996.

Mooser, F.: Historia geológica de la Cuenca de México, Technical report, System of deep drainage in Mexico City, book I, 7-38, 1975.

Pérez-Flores, M. A., Mendez-Delgado, S., and Gómez-Treviño, E.: Imaging low-frequency and dc electromagnetic fields using a simple linear approximation, Geophysics, 66, 1067-1081, 2001.

Sasaki, Y.: Two-dimensional joint inversion of magnetotelluric and dipole-dipole resistivity data, Geophysics, 54, 256-262, 1989.

Urrutia-Fucugauchi, J.: Paleomagnetic constraints on spatial/temporal volcanic activity in the Santa Catarina-chalco region Southeastern basin of Mexico, Geofísica Internacional, 34, 1, 55-66, 1995. 